\title{
Modeling CO Oxidation on Silica-Supported Iron Oxide under Transient Conditions
}

\author{
Harvey Randall, Ralf Doepper, and Albert Renken* \\ Institute of Chemical Enginering, Swiss Federal Institute of Technology, CH-1015 Lausanne, Switzerland
}

\begin{abstract}
The oxidation of $\mathrm{CO}$ on silica-supported hematite $\left(\mathrm{Fe}_{2} \mathrm{O}_{3}\right)$ was studied by the step-response method in a tubular fixed-bed reactor, at temperatures ranging between 270 and $350{ }^{\circ} \mathrm{C}$. The oxidation process appeared to proceed through two stages. Firstly, oxygen atoms adsorbed on the surface of hematite react with gas phase $\mathrm{CO}$ according to an Eley-Rideal mechanism. Once that adsorbed oxygen has been consumed to some extent, surface oxygen from the lattice of iron oxide is removed in a second stage involving $\mathrm{CO}$ adsorption and $\mathrm{CO}$ reactive desorption steps, thus generating surface oxygen vacancies. Further reduction of hematite proceeds through diffusion of subsurface oxygen into surface oxygen vacancies. On this basis, a kinetic model was developed, which quantitatively describes the transient behavior of the oxidation process. The activation energies and pre-exponential factors of the rate constants and characteristic subsurface oxygen diffusion time could be determined.
\end{abstract}

\section{Introduction}

The oxidation of $\mathrm{CO}$ is an important step during the overall reduction of $\mathrm{NO}$ with $\mathrm{CO}$ on $\mathrm{Fe}_{2} \mathrm{O}_{3} / \mathrm{SiO}_{2}$. $\mathrm{NO}$ and $\mathrm{N}_{2} \mathrm{O}$ reduction only occur on reduced catalysts $\left(\mathrm{Fe}_{3} \mathrm{O}_{4}\right)$, by reaction with surface oxygen vacancies. As a result, the catalyst is reoxidized to hematite, which is no longer active for reducing $\mathrm{NO}$ and $\mathrm{N}_{2} \mathrm{O}$ (Randall et al., 1996a,b). The role of CO is to reduce the catalyst in order to maintain a sufficient concentration of surface oxygen vacancies for $\mathrm{NO}$ and $\mathrm{N}_{2} \mathrm{O}$ reduction to take place. The aim of this work is to provide a quantitative description of the reduction of $\mathrm{Fe}_{2} \mathrm{O}_{3} / \mathrm{SiO}_{2}$ by $\mathrm{CO}$, which could eventually be applied to the overall reduction of $\mathrm{NO}$ or $\mathrm{N}_{2} \mathrm{O}$ by CO. As a matter of fact, the number of kinetic parameters to be adjusted to experimental data is considerably reduced by a study of the interaction of $\mathrm{CO}$ with the catalyst independently.

In this work, the step-response method-which consists of measuring the response of a catalytic system to a square like change in concentration of the reactants-was chosen for its simplicity of application and for the substantial amount of mechanistic information that it provides (Kobayashi 1974, 1982; Bennett, 1976; Tamaru, 1983; Kiperman, 1991; Renken, 1993). We found it important to perform step changes in a wide range of state variables such as temperature, flow rate, and $\mathrm{CO}$ concentration, in order to obtain a meaningful kinetic model with reliable values of its parameters.

\section{Experimental Section}

Transient experiments were carried out in a flow apparatus consisting of two separate feed sections converging to a four-way valve, which allowed generation of concentration step changes at the reactor inlet. Both feeds contained pure gases ( $>99.99 \%$, Carbagas, Lausanne, Switzerland). The reactor used in this study was a glass fixed-bed tubular reactor (internal diameter, $5 \mathrm{~mm}$; length, $300 \mathrm{~mm}$ ), which can be considered as a plug flow reactor, as shown previously (Randall et al., 1996b). The catalyst was $\mathrm{Fe}_{2} \mathrm{O}_{3} / \mathrm{SiO}_{2}\left(200<\mathrm{d}_{\mathrm{p}}<250\right.$ $\mu \mathrm{m})$ which was prepared by iron nitrate impregnation and calcination (Randall et al., 1996a). For the experi-

* Author to whom correspondence should be addressed. E-mail: Albert.Renken@igc.dc.epfl.ch.

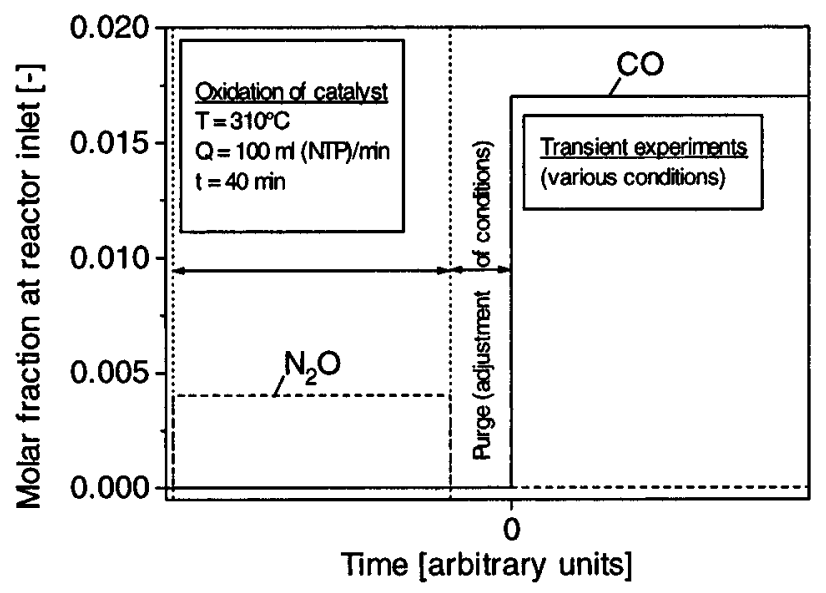

Figure 1. $\mathrm{N}_{2} \mathrm{O}$ and $\mathrm{CO}$ molar fraction at reactor inlet as a function of time for catalyst pretreatment (oxidation with $\mathrm{N}_{2} \mathrm{O}$ ) and subsequent reduction with $\mathrm{CO}$.

ments, $250 \mathrm{mg}$ of catalyst was used. Gases at the reactor outlet stream were analyzed with a quadrupole mass spectrometer (QMG420, Balzers AG, Balzers, Principality of Liechtenstein). Prior to transient experiments, the catalyst was oxidized in a flow of $\mathrm{N}_{2} \mathrm{O}\left(\mathrm{y}_{\mathrm{N}_{2} \mathrm{O}, 0}\right.$ $=0.004, \mathrm{Q}=100 \mathrm{~mL}(\mathrm{NTP}) / \mathrm{min}, \mathrm{p}=150 \mathrm{kPa})$ at 310 ${ }^{\circ} \mathrm{C}$ for $40 \mathrm{~min}$, which assures total oxidation to $\mathrm{Fe}_{2} \mathrm{O}_{3}$ (Randall et al., 1996b). The $\mathrm{N}_{2} \mathrm{O}$ feed was then changed to pure $A r$, and the temperature of the catalyst was set to the desired value. Transient experiments then consisted in step changes of CO inlet mole fraction (from 0 to $y_{(0,0)}$, performed by the substitution of the Ar flow with a mixture of $\mathrm{CO}$ and $\mathrm{Ar}$ (same pressure and flow rate). The molar fractions of $\mathrm{N}_{2} \mathrm{O}$ and $\mathrm{CO}$ generated at the reactor inlet respectively for catalyst oxidation and catalyst reduction are depicted in Figure 1 . These transients were performed at different temperatures $\left(251<\mathrm{T}<351{ }^{\circ} \mathrm{C}\right)$, inlet $\mathrm{CO}$ mole fractions $\left(0.01<\mathrm{y}_{\mathrm{CO}, 0}\right.$ $<0.03$ ), and flow rates $(50<\mathrm{Q}<200 \mathrm{~mL}$ (NTP)/min). All transients were found to be almost isothermal: the temperature change during experiments never exceeded $1.5^{\circ} \mathrm{C}$. The slight deviation of the inlet function $\mathrm{y}_{\mathrm{CO}, 0}$ $(\mathrm{t})$-which is generated at the reactor inlet after the inlet flow was switched from pure $\mathrm{Ar}$ to $\mathrm{CO} / \mathrm{Ar}$-from the ideal square function was taken into account for modeling of the different experimental flow rates and $\mathrm{CO}$ feed concentrations. Effect of internal diffusion of gaseous 


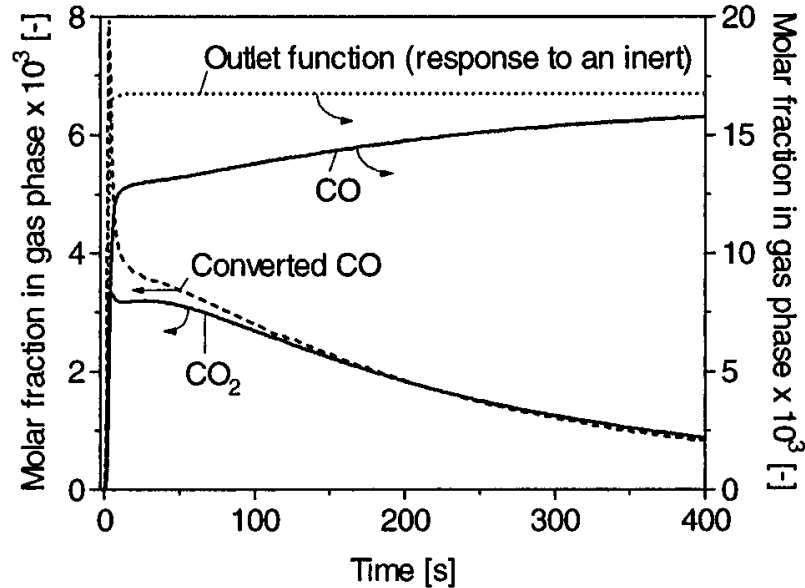

Figure 2. Response to a $\mathrm{CO}$ concentration step on an oxidized catalyst. Conditions: $\mathrm{T}=310^{\circ} \mathrm{C}, \mathrm{y}_{\mathrm{CO}, 0}=0.017, \mathrm{Q}=100 \mathrm{~mL}$ (NTP)/ $\min$.

$\mathrm{CO}$ is negligible, as previously shown by the comparison of transient experiments with different particle sizes (Randall et al., 1996c). Moreover, no external transport limitations were encountered, since the rate of external transport of gaseous CO was estimated to be 800 times higher than the highest measured $\mathrm{CO}$ oxidation rate.

A more detailed description of the experimental setup and procedures is given elsewhere (Randall et al., 1996a).

\section{Results and Discussion}

Qualitative Interpretation of Transients. Figure 2 shows a typical transient response of the catalyst to a concentration step of CO over an oxidized catalyst (conditions: $\mathrm{T}=310{ }^{\circ} \mathrm{C}, \mathrm{y}_{\mathrm{co}, 0}=0.017, \mathrm{Q}=100 \mathrm{~mL}$ (NTP)/min). The response of $\mathrm{CO}_{2}$ shows an instantaneous maximum, followed by a second broader maximum. After a few hundred seconds, the reaction rate falls to very low values, but $\mathrm{CO}_{2}$ is still observed for over an hour. During the first hundred seconds of the transient, the amount of converted CO (calculated by subtracting the response of $\mathrm{CO}$ to the outlet function, i.e. the response to a step wise increase in concentration of an inert tracer with the same inlet concentration as $\mathrm{CO}$ ) is higher than the amount of $\mathrm{CO}_{2}$ formed, indicating that a carbon-containing species is adsorbed on the catalyst. Thereafter, the $\mathrm{CO}_{2}$ response becomes higher than the response of converted $\mathrm{CO}$, indicating that, in this period, the rate of $\mathrm{CO}$ adsorption is lower than the rate of $\mathrm{CO}_{2}$ formation. The carbon-bal ance defect was observed for all experimental runs.

The appearance of two maxima in the $\mathrm{CO}_{2}$ responses indicates that $\mathrm{CO}$ oxidation takes place in two stages. The first step can certainly be described by an EleyRideal reaction between gas phase $\mathrm{CO}$ and surface oxygen, since the first maximum is instantaneous. The appearance of the second maximum can be explained by the reaction of $\mathrm{CO}$ at another type of surface sites, which are not present in a sufficient amount at the beginning of the experiment and which are produced during the first Eley-Rideal step. Furthermore, the carbon-balance defect encountered during thetransients implies that the second reduction process of the catalyst must include a carbon-containing surface species. Finally, the tailing of the $\mathrm{CO}$ and $\mathrm{CO}_{2}$ responses is presumably due to thelimitation of the reduction of the catalyst by subsurface oxygen diffusion, as was observed for the oxidation of the catalyst by $\mathrm{N}_{2} \mathrm{O}$ and $\mathrm{NO}$ (Randall et al., 1996a,b). Upon oxidation of magnetite with subsequent pulses of $\mathrm{N}_{2} \mathrm{O}$ and $\mathrm{Ar}$ (Randall, 1996c), it was shown that, after a period under $\mathrm{Ar}$, the rate of oxidation of the catalyst by $\mathrm{N}_{2} \mathrm{O}$ is higher than the rate at the end of the previous period under $\mathrm{N}_{2} \mathrm{O}$. This phenomena was shown to occur through diffusion of oxygen abstracted from $\mathrm{N}_{2} \mathrm{O}$ at the surface of the catalyst into subsurface oxygen vacancies. As a result, the concentration of surface oxygen vacancies increases during the period under Ar, and consequently the rate of oxidation of the surface upon recontacting the catalyst with $\mathrm{N}_{2} \mathrm{O}$ is higher than the rate at the end of the previous period under $\mathrm{N}_{2} \mathrm{O}$. This behavior cannot be described by a simple shrinking core model, for which there is no effect on the rate of oxidation of the catalyst when it contacts an inert gas, since there is no possible equilibration of the concentrations of solid species (lattice oxygen and lattice oxygen vacancies) during this period. Furthermore, the shrinking core model consists of a reaction zone moving toward the center of the particle whereas, in our case, the reaction between $\mathrm{N}_{2} \mathrm{O}$ and surface oxygen vacancies only takes place at the outer surface of the solid, since $\mathrm{N}_{2} \mathrm{O}$ has no access into the bulk of the catalyst.

By investigating the formation of adsorbed oxygen on $\mathrm{Fe}_{2} \mathrm{O}_{3}$ and $\mathrm{NiO}$ by temperature-programmed desorption, I wamoto et al. (1976, 1978a,b) have demonstrated the existence of at least four states of adsorbed oxygen, the maxima of which appeared at $50-300(\alpha), 350-360(\beta)$, 480-490 $(\gamma)$, and $>600{ }^{\circ} \mathrm{C}(\delta)$, respectively. $\gamma$ and $\delta$ oxygen were assigned to $\mathrm{O}^{-}$species adsorbed on different surface sites. Furthermore, by measuring the change in el ectrical conductivity of $\mathrm{Fe}_{2} \mathrm{O}_{3}$ in $\mathrm{NO}$ and $\mathrm{N}_{2} \mathrm{O}$ atmospheres, Sazonova et al. (1977) showed that negatively charged particles are formed, which they assigned to adsorbed $\mathrm{O}^{-}$or adsorbed $\mathrm{N}_{2} \mathrm{O}^{-}$species. Evidence for the existence of adsorbed oxygen atoms $\left(\mathrm{O}^{-}\right)$on $\mathrm{NiO}$ was also found by determination of the mean el ectric charges acquired by an oxygen atom on a NiO surface (Bieranski and Najbar, 1972), or by means of XPS (Robert et al., 1972). Similarly, Alkhazov et al. (1976) have reported the formation of adsorbed oxygen on $\mathrm{Cr}_{2} \mathrm{O}_{3}$, which they call excess oxygen. Sokolovskii (1990), proposed a generalized scheme that applies for oxidative catalysis on solid oxides. He suggests a twostep oxygen activation process, by which a primary activated form of surface oxygen (radical ion form such as $\mathrm{O}^{-}$or $\mathrm{O}_{2}^{-}$) is first formed, which subsequently transforms into less active oxygen of the catalyst lattice. Dekker (1995) found that reduction of alumina-supported copper oxide proceeds according to a two-step mechanism, involving two different types of surface oxygen: the first type reacts via an Eley-Rideal mechanism, whereas the second type reacts via a LangmuirHinshel wood mechanism.

In a previous study (Randall, 1996c), it was shown that the amount of oxygen that can be transferred to the catalyst (oxygen capacity) is $16 \%$ higher than the amount of oxygen corresponding to the transformation of $\mathrm{Fe}_{2} \mathrm{O}_{3}$ to $\mathrm{Fe}_{3} \mathrm{O}_{4}$ by performing successive reductionoxidation cycles of $\mathrm{Fe}_{2} \mathrm{O}_{3}$ to $\mathrm{Fe}_{3} \mathrm{O}_{4}$ with $\mathrm{CO}$ and $\mathrm{N}_{2} \mathrm{O}$, respectively. This observation is consistent with the formation of adsorbed oxygen on $\mathrm{Fe}_{2} \mathrm{O}_{3}$ during treatment with $\mathrm{N}_{2} \mathrm{O}$.

On the basis of the qualitative analysis of the transient responses of oxidized catalysts to concentration steps of CO combined to the information from literature cited above, the following three-step mechanism is proposed for CO oxidation (eqs 1, 2, and 3). In eqs 1, 2, and $3, \mathrm{O}(\mathrm{O})$ represents an oxygen atom adsorbed on an oxidized site from the surface of iron oxide, $(\mathrm{O})$ stands 


$$
\begin{gathered}
\mathrm{CO}+\mathrm{O}(\mathrm{O}) \stackrel{\mathrm{ker}_{\mathrm{er}}}{\longrightarrow} \mathrm{CO}_{2}+(\mathrm{O}) \\
\mathrm{CO}+(\mathrm{O}) \stackrel{\mathrm{k}_{\mathrm{ad}}}{\longrightarrow} \mathrm{CO}(\mathrm{O}) \\
\mathrm{CO}(\mathrm{O}) \stackrel{\mathrm{k}_{\mathrm{d}}}{\longrightarrow} \mathrm{CO}_{2}+()
\end{gathered}
$$

for surface oxygen from the iron oxide lattice, and ( ) symbolizes a surface oxygen vacancy. For a CO concentration step on an oxidized catalyst, the first step (eq 1) leads to an immediate production of $\mathrm{CO}_{2}$ (first maximum). CO adsorption (eq 2) takes place only once the adsorbed oxygen $(\mathrm{O}(\mathrm{O})$ ) has been consumed to some extent, and finally the reactive desorption of adsorbed $\mathrm{CO}$ (eq 3) leads to a secondary formation of $\mathrm{CO}_{2}$ (second maximum). Further reduction of the catalyst proceeds through diffusion of subsurface lattice oxygen into surface oxygen vacancies. The surface reaction and the subsurface diffusion processes are schematically described in Figure 3.

Model Equations. Rate Equations. The kinetics of the three steps of CO oxidation (eqs 1, 2, and 3) were described using the following rate equations:

$$
\begin{gathered}
r_{\mathrm{er}}=k_{\mathrm{er}} c_{\mathrm{CO}} \theta_{\mathrm{OO}} \\
r_{\mathrm{ad}}=k_{\mathrm{ad}} c_{\mathrm{CO}} \theta_{\mathrm{O}} \\
r_{\mathrm{d}}=k_{\mathrm{d}} \theta_{\mathrm{CO}}
\end{gathered}
$$

The surface coverages are defined as

$$
\theta_{\mathrm{k}}=\mathrm{c}_{\mathrm{k}} / \mathrm{N}_{\mathrm{s}}
$$

$\mathrm{N}_{\mathrm{s}}$, the total amount of sites, was taken as the amount of oxygen corresponding to the transformation of $\mathrm{Fe}_{2} \mathrm{O}_{3}$ to $\mathrm{Fe}_{3} \mathrm{O}_{4}$. A value of $\mathrm{N}_{\mathrm{s}}=0.33 \mathrm{~mol} / \mathrm{kg}_{\text {cat }}$ was obtained (Randall, 1996c).

Mass Balance for Gas Phase Species in a Nonstationary Tubular Plug Flow Reactor. The mass balance equation for a gas phase species j ( $\mathrm{CO}$ or $\left.\mathrm{CO}_{2}\right)$ is given by the expression

$$
\frac{\partial \mathrm{c}_{\mathrm{j}}}{\partial \mathrm{t}}=-\frac{1}{\tau} \frac{\partial \mathrm{c}_{\mathrm{j}}}{\partial \mathrm{x}}+\mathrm{R}_{\mathrm{j}} \rho_{\mathrm{cat}} \frac{1-\epsilon_{\mathrm{b}}}{\epsilon_{\mathrm{b}}}
$$

Variables and parameters are defined in the Nomenclature section.

$\tau$ in eq 8 is the space-time referred to gas volume. The rate $R_{j}$ in eq 8 is given by

$$
\begin{gathered}
\mathrm{R}_{\mathrm{CO}}=-\mathrm{r}_{\mathrm{er}}-\mathrm{r}_{\mathrm{ad}} \\
\mathrm{R}_{\mathrm{CO}_{2}}=\mathrm{r}_{\mathrm{er}}+\mathrm{r}_{\mathrm{d}}
\end{gathered}
$$

For a CO concentration step from 0 to $y_{C o, 0}$ at $t=0$, the initial condition for gas phase species $\left(\mathrm{CO}\right.$ or $\left.\mathrm{CO}_{2}\right)$ is

$$
c_{j}(x, 0)=0
$$

and the boundary conditions at the reactor inlet $(x=0)$ are given by

$$
\left.\begin{array}{l}
c_{\mathrm{CO}}(0, t)=(p / R T) y_{\mathrm{CO}, 0}(t) \\
c_{\mathrm{CO}_{2}}(0, t)=0
\end{array}\right\}
$$

Mass Balance for Surface Species. F or adsorbed oxygen and adsorbed $\mathrm{CO}$ species, the following mass balance equations apply:

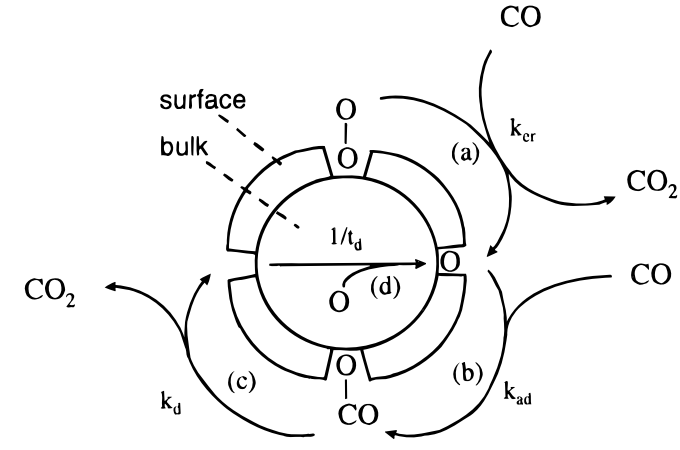

Figure 3. Schematic representation of the reduction of an iron oxide crystallite by CO: (a) Eley-Rideal reaction, (b) CO adsorption, (c) CO reactive desorption, (d) subsurface oxygen diffusion. $t_{d}=$ characteristic diffusion time.

$$
\begin{gathered}
\left(\partial \theta_{\mathrm{Oo}} / \partial \mathrm{t}\right)=\left(-\mathrm{r}_{\mathrm{er}} / \mathrm{N}_{\mathrm{s}}\right) \\
\left(\partial \theta_{\mathrm{co}} / \partial \mathrm{t}\right)=\left(\left(\mathrm{r}_{\mathrm{ad}}-\mathrm{r}_{\mathrm{d}}\right) / \mathrm{N}_{\mathrm{s}}\right)
\end{gathered}
$$

The dimensionless concentration of lattice oxygen, $\theta_{0}$, is a function of $x, z$, and $t$, where $z$ is the distance into the iron oxide layer.

For spherical iron oxide crystallites, the dimensionless mass balance equation for $\theta_{0}$ at the surface $(z=1$, where $\theta_{0}=\theta_{0, s}$ ) is

$$
\frac{\partial \theta_{\mathrm{O}, \mathrm{s}}}{\partial \mathrm{t}}(\mathrm{x}, \mathrm{z}=1, \mathrm{t})=\frac{1}{\mathrm{t}_{\mathrm{d}}}\left(\frac{\partial^{2} \theta_{\mathrm{O}}}{\partial \mathrm{z}^{2}}+2 \frac{\partial \theta_{\mathrm{O}}}{\partial \mathrm{z}}\right)_{\mathrm{z}=1}+\frac{\mathrm{r}_{\mathrm{er}}-\mathrm{r}_{\mathrm{ad}}}{\mathrm{N}_{\mathrm{s}}}
$$

where $t_{d}$ is the characteristic diffusion time of oxygen into the iron oxide layer.

In the bulk of the iron oxide layer $(z<1)$, where no reaction occurs

$$
\frac{\partial \theta_{\mathrm{O}}}{\partial \mathrm{t}}(\mathrm{x}, \mathrm{z}<1, \mathrm{t})=\frac{1}{\mathrm{t}_{\mathrm{d}}}\left(\frac{\partial^{2} \theta_{\mathrm{O}}}{\partial \mathrm{z}^{2}}+\frac{2}{\mathrm{z}} \frac{\partial \theta_{\mathrm{O}}}{\partial \mathrm{z}}\right)
$$

For a totally oxidized catalyst, the initial conditions for eqs $13,14,15$, and 16 are the following (the hypothesis was made that the surface is initially totally covered with adsorbed oxygen $\mathrm{O}(\mathrm{O})$ ):

$$
\begin{gathered}
\theta_{\mathrm{OO}}(\mathrm{x}, 0)=1 \\
\theta_{\mathrm{CO}}(\mathrm{x}, 0)=0 \\
\theta_{\mathrm{O}}(\mathrm{x}, \mathrm{z}<1,0)=1 \\
\theta_{\mathrm{O}}(\mathrm{x}, \mathrm{z}=1,0)=0
\end{gathered}
$$

The iron oxide crystallites on the surface of the silica support can be considered to be symmetrical around their centerplanes. Therefore, the boundary condition at the center $(z=0)$ of the particle is

$$
\frac{\partial \theta_{\mathrm{O}}}{\partial \mathrm{z}}(\mathrm{x}, 0, \mathrm{t})=0
$$

The system of partial differential equations in eqs 8 , $13,14,15$, and 16 was solved using the finite difference approximation method (Simusolv, 1990; Crank 1957), using nine nodes in the $x$ direction and 40 nodes in the $z$ direction; these are the minimum number of nodes above which the calculated responses did not change any further. Numerical integration was carried out using a variable step algorithm (Gear) (Simusolv, 1990). Optimization of parameters $t_{d}, k_{e r}, k_{a d}$, and $k_{d}$ was performed by fitting the calculated molar fractions of 

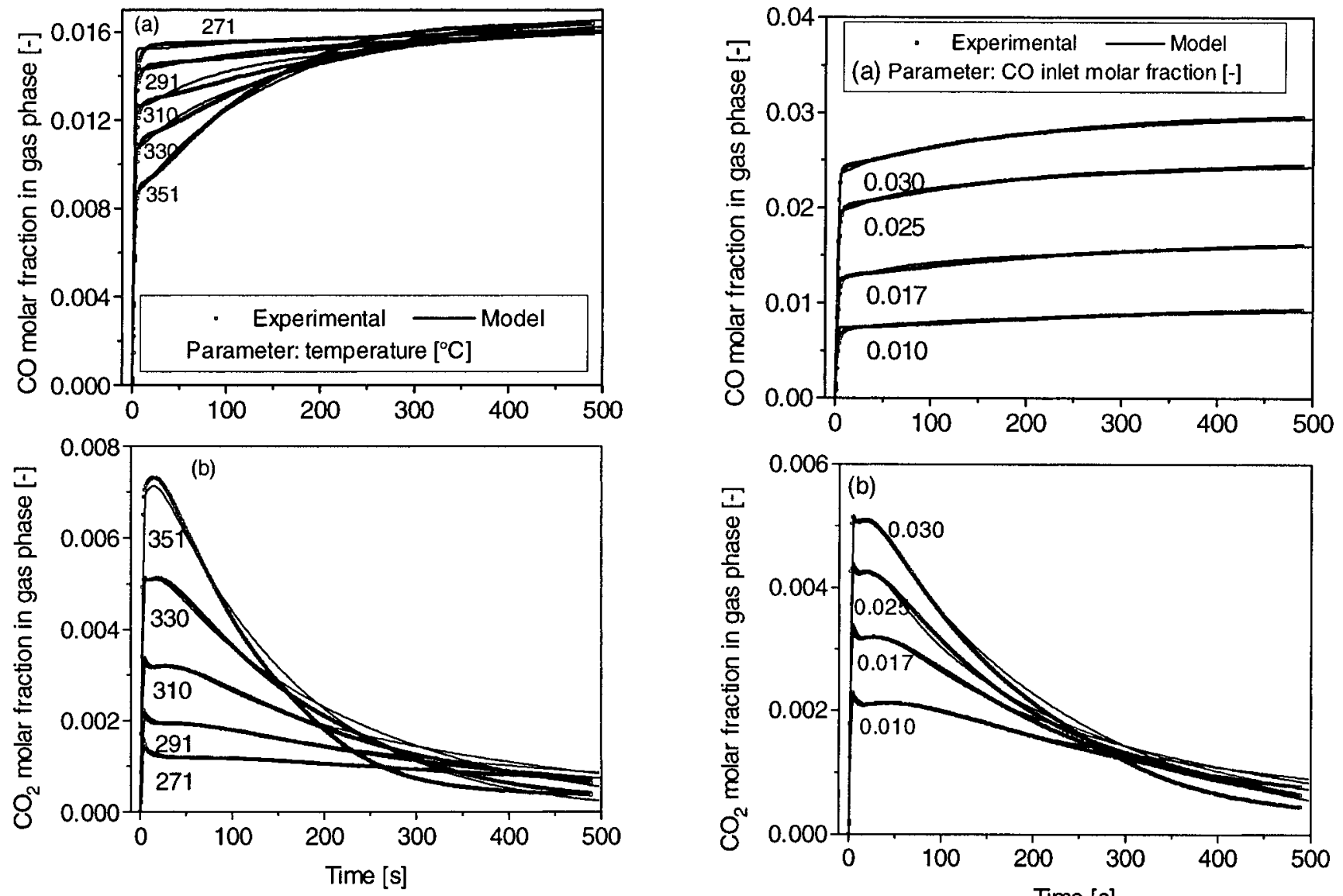

Figure 4. Comparison between model and experiment for a CO concentration step on an oxidized catalyst at different temperatures. Conditions: $\mathrm{y}_{\mathrm{CO}, 0}=0.017, \mathrm{Q}=100 \mathrm{~mL}$ (NTP)/min. (a) $\mathrm{CO}$ response, (b) $\mathrm{CO}_{2}$ response.

$\mathrm{CO}$ and $\mathrm{CO}_{2}$ at the outlet of the reactor to their experimental values, using the Nelder-Mead search algorithm and the likelihood function as the objective function (Simusolv, 1990). Initial estimates for parameters $k_{e r}$ and $t_{d}$, which essentially affect the first peak in the $\mathrm{CO}_{2}$ response and the tailing in the $\mathrm{CO}_{2}$ response, respectively, were readily obtained. In order to obtain two maxima in the $\mathrm{CO}_{2}$ response, it was found that parameters $k_{a d}$ and $k_{d}$ have to be of the same order of magnitude. Finally, the optimum values of parameters were determined by simultaneous optimization of all parameters using different sets of initial estimates for $\mathrm{k}_{\mathrm{ad}}$ and $\mathrm{k}_{\mathrm{d}}$.

Parameter Estimation. In Figures 4 and 5, the experimental transient responses at various temperatures and inlet $\mathrm{CO}$ mole fractions are compared to the calculated responses with optimum values of parameters $t_{d}, k_{e r}, k_{a d}$, and $k_{d}$. As can be seen from these figures, the three-step oxidation model of eqs 1, 2, and 3 , combined with subsurface diffusion of lattice oxygen, allows us to predict the transient reduction of the catalyst over a wide range of the dependent variables $\mathrm{T}$ and $\mathrm{y}_{\mathrm{co}, 0}$. Similar fittings were obtained at other flow rates. The model is able to describe the increase in the ratio of the intensities of the second maximum to the first maximum with temperature as well as the shift of the second maximum to shorter times with increasing temperature. The shift of the second maximum to shorter times with increasing $\mathrm{CO}$ inlet molar fraction is also properly described. However, a divergence between model and experiment is observed at high reaction times ( $\mathrm{t}>200-300 \mathrm{~s}$ ), which may be due to the fact that subsurface diffusion was modeled in spherical coordinates, whereas the structure of iron

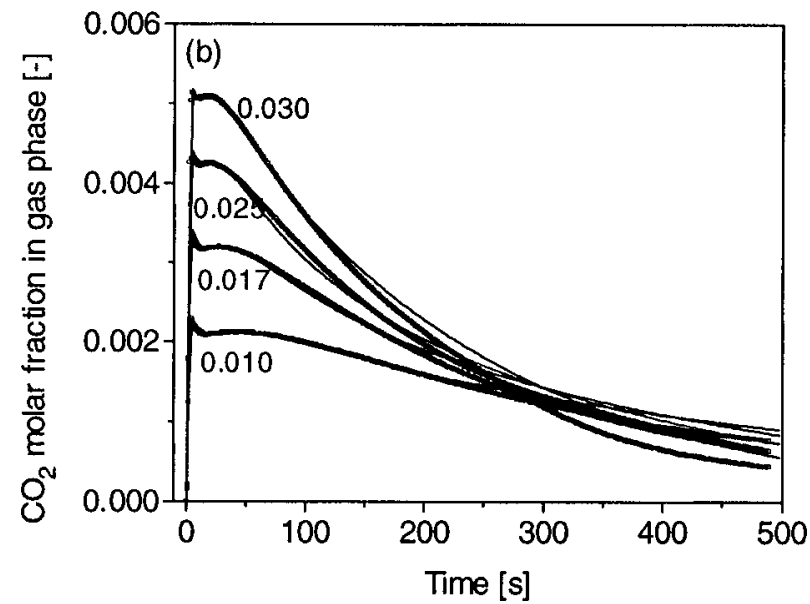

Figure 5. Comparison between model and experiment for a $\mathrm{CO}$ concentration step on an oxidized catalyst at different inlet CO molar fractions. Conditions: $\mathrm{T}=310^{\circ} \mathrm{C}, \mathrm{Q}=100 \mathrm{~mL}(\mathrm{NTP}) / \mathrm{min}$.

(a) $\mathrm{CO}$ response, (b) $\mathrm{CO}_{2}$ response.

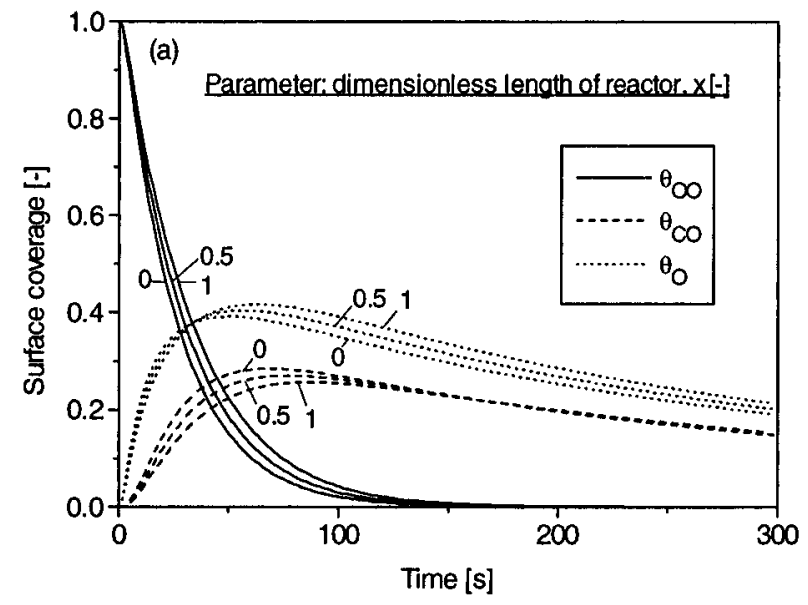

Figure 6. Calculated responses of catalyst surface species at different positions $\mathrm{x}$ in the reactor for a CO concentration step on an oxidized catalyst. Conditions: $\mathrm{T}=310^{\circ} \mathrm{C}, \mathrm{y}_{\mathrm{co}, 0}=0.017, \mathrm{Q}=$ $100 \mathrm{~mL}(\mathrm{NTP}) / \mathrm{min}$.

oxide crystallites may differ significantly from the ideal spherical geometry.

Figure 6 gives the calculated spatiotemporal behavior of catalyst surface species (at $z=1$ ) with optimum values of parameters, at $\mathrm{T}=310^{\circ} \mathrm{C}, \mathrm{y}_{\mathrm{co}, 0}=0.017$, and $\mathrm{Q}=100 \mathrm{~mL}(\mathrm{NTP}) / \mathrm{min}$. $\theta_{\mathrm{OO}}$ decreases relatively fast due to the Eley-Rideal reaction between adsorbed oxygen and gas phase $C O$. As a result, $\theta_{\mathrm{O}}$ at the surface rises and, subsequently, goes through a maximum at approximately $70 \mathrm{~s}$ due to $\mathrm{CO}$ adsorption on surface lattice oxygen. At the beginning of the transient, $\mathrm{CO}$ adsorption is faster than CO reactive desorption, leading 
Table 1. Activation Energies and Pre-exponential Factors

\begin{tabular}{|c|c|c|c|c|c|c|c|}
\hline $\begin{array}{c}10^{4} \mathrm{k}_{\mathrm{er} 0} \\
{\left[\mathrm{~m}^{3} / \mathrm{kg}_{\mathrm{cat}} \cdot \mathrm{s}\right]}\end{array}$ & $\begin{array}{c}10^{4} \mathrm{k}_{\mathrm{ado} 0} \\
{\left[\mathrm{~m}^{3} / \mathrm{kg}_{\mathrm{cat}} \cdot \mathrm{s}\right]}\end{array}$ & $\begin{array}{c}10^{5} \mathrm{k}_{\mathrm{d} 0} \\
{\left[\mathrm{~mol} / \mathrm{kg}_{\mathrm{cat}} \cdot \mathrm{s}\right]}\end{array}$ & $\begin{array}{c}10^{3}\left(1 / t_{d 0}\right) \\
{\left[s^{-1}\right]}\end{array}$ & $\begin{array}{c}\mathrm{E}_{\mathrm{er}} \\
{[\mathrm{kJ} / \mathrm{mol}]}\end{array}$ & $\begin{array}{c}E_{\text {ad }} \\
{[\mathrm{kJ} / \mathrm{mol}]}\end{array}$ & $\begin{array}{c}E_{d} \\
{[\mathrm{~kJ} / \mathrm{mol}]}\end{array}$ & $\begin{array}{c}E_{\text {diff }} \\
{[\mathrm{kJ} / \mathrm{mol}]}\end{array}$ \\
\hline $1.3 \pm 0.6$ & $1.1 \pm 0.4$ & $2.7 \pm 1.6$ & $1.4 \pm 1.6$ & $75 \pm 2$ & $73 \pm 2$ & $88 \pm 3$ & $69 \pm 7$ \\
\hline
\end{tabular}

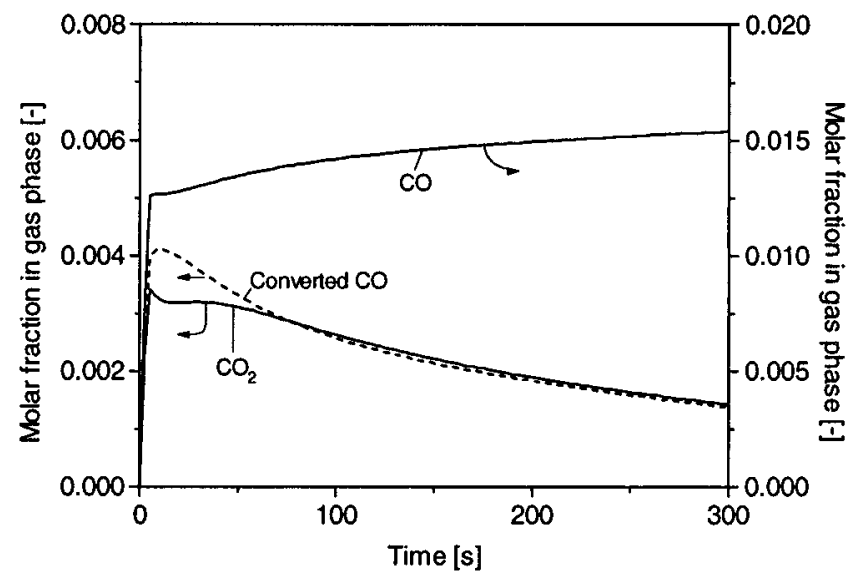

Figure 7. Calculated gas phase responses for a $\mathrm{CO}$ concentration step on an oxidized catalyst. Conditions: $\mathrm{T}=310^{\circ} \mathrm{C}, \mathrm{y}_{\mathrm{co}, 0}=0.017$, $\mathrm{Q}=100 \mathrm{~mL}(\mathrm{NTP}) / \mathrm{min}$.

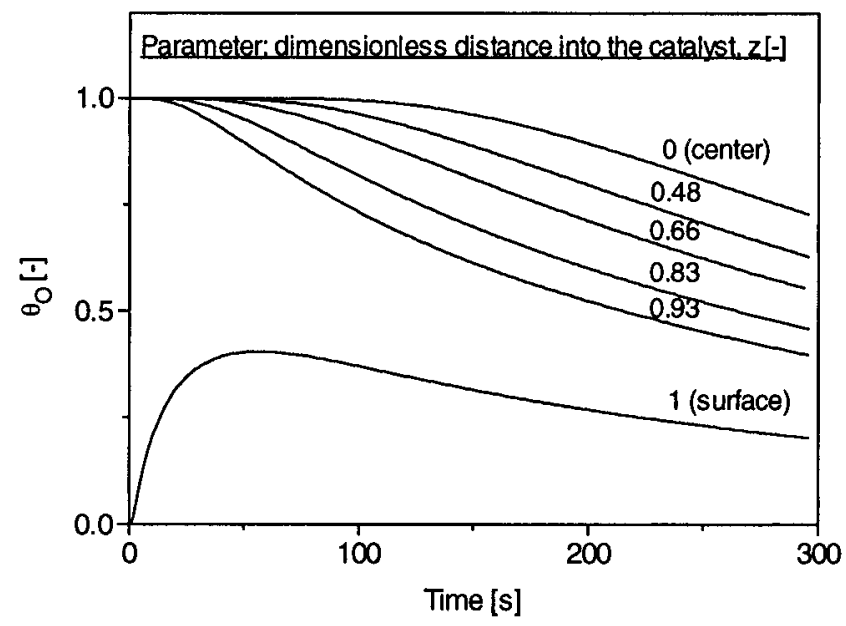

Figure 8. Calculated spatiotemporal behavior of catalyst surface and bulk lattice oxygen at $\mathrm{x}=0.5$ (middle of reactor) for a $\mathrm{CO}$ concentration step on an oxidized catalyst. Conditions: $\mathrm{T}=310$ ${ }^{\circ} \mathrm{C}, \mathrm{y}_{\mathrm{CO}, 0}=0.017, \mathrm{Q}=100 \mathrm{~mL}(\mathrm{NTP}) / \mathrm{min}$.

to an accumulation of adsorbed $\mathrm{CO}$. As a result, the amount of converted $\mathrm{CO}$ exceeds the $\mathrm{CO}_{2}$ response (Figure 7). After $70 \mathrm{~s}$, the diminution of $\theta_{0}$ at the surface causes a faster rate for $\mathrm{CO}$ reactive desorption than for $\mathrm{CO}$ adsorption. Consequently, the amount of converted $\mathrm{CO}$ becomes lower than the that from the $\mathrm{CO}_{2}$ response. Accordingly, the maximum in $\theta_{0}$ at the reactor outlet and for $z=1$ (surface) arises at the same time (approximately $70 \mathrm{~s}$ ) as the crossing between $\mathrm{CO}_{2}$ and converted $\mathrm{CO}$ responses.

Thus, the model accounts for the complex relation between the responses of $\mathrm{CO}_{2}$ and adsorbed $\mathrm{CO}$ encountered experimentally (Figure 2 ). The decrease in $\theta_{\mathrm{CO}}$ and $\theta_{0}$ at the surface after $70 \mathrm{~s}$ is relatively slow, since lattice oxygen is slowly transferred to the surface by diffusion from the bulk of the iron oxide. This last point is depicted in Figure 8, where $\theta_{0}$ in the middle of the reactor $(x=0.5)$ at different positions in the catalyst (z) is plotted versus time. The resistance to oxygen transfer in the catalyst gives rise to a gradient of $\theta_{0}$ as a function of $z$. Due to this resistance, the beginning of the diminution in $\theta_{\mathrm{O}}$ is increasingly delayed when it approaches the center of the particle (i.e. with decreasing values of $\mathrm{z}$ ).

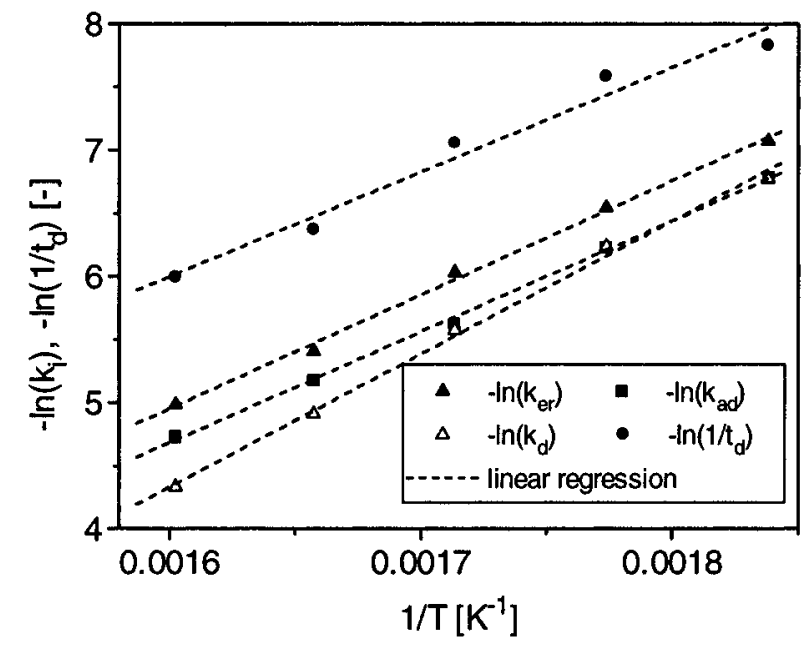

Figure 9. Arrhenius plot for the rate constants $\left(k_{e r}, k_{a d}\right.$, and $\left.k_{d}\right)$ and the reverse characteristic diffusion time $\left(1 / t_{d}\right)$.

The optimum values of parameters $1 / t_{d}, k_{e r}, k_{a d}$, and $k_{d}$ obtained for all runs were used to determine the activation energies and pre-exponential factors of the corresponding reaction or diffusion processes (Table 1 ). All parameters could be fitted with the Arrhenius law, as shown in Figure 9, where the natural logarithms of their values are plotted versus reverse temperature (for $\mathrm{T}=310^{\circ} \mathrm{C}$, the average values of parameters obtained for the different runs performed at this temperature are plotted). The value obtained in the present work for $\mathrm{E}_{\text {diff }}(69 \pm 7 \mathrm{~kJ} / \mathrm{mol})$ during reduction of hematite is close to the values obtained by Castle and Surmann (1969) $(71 \mathrm{~kJ} / \mathrm{mol}$ ) and Heizmann et al . (1973) (109 kJ /mol) for oxygen diffusion in $\mathrm{Fe}_{3} \mathrm{O}_{4}$ or Gillot (1981) for diffusion of iron ions in hematite $(89.9 \mathrm{~kJ} / \mathrm{mol})$.

\section{Conclusions}

A model was developed which quantitatively describes the reduction of hematite by $\mathrm{CO}$ under transient conditions within a wide range of the state variables (temperature, $\mathrm{CO}$ concentration, and flow rate). The model consists of three surface reaction steps as well as subsurface oxygen diffusion. It accounts for the complex features of the transient behavior of gas phase species ( $\mathrm{CO}$ and $\mathrm{CO}_{2}$ ) such as a carbon-balance defect, a twostage reduction process, and a long tailing in the transient responses. The rate constants and the diffusion coefficient of oxygen in the iron oxide follow the Arrhenius law.

\section{Acknowledgment}

We are grateful for financial support of this project by the Swiss National Science Foundation.

\section{Nomenclature}

$\mathrm{c}_{\mathrm{CO}}=$ gas phase concentration of $\mathrm{CO}, \mathrm{mol} / \mathrm{m}^{3}$

$\mathrm{C}_{\mathrm{CO}_{2}}=$ gas phase concentration of $\mathrm{CO}_{2}, \mathrm{~mol} / \mathrm{m}^{3}$

$\mathrm{C}_{\mathrm{CO}, 0}(\mathrm{t})=\mathrm{CO}$ inlet concentration step function, $\mathrm{mol} / \mathrm{m}^{3}$

$\left.c_{1}\right)=$ oxygen vacancy concentration in the catalyst, $\mathrm{mol} /$ $\mathrm{kg}_{\text {cat }}$

$c_{(0)}=$ lattice oxygen concentration in the catalyst, $\mathrm{mol} / \mathrm{kg}_{\mathrm{cat}}$ $\mathrm{C}_{\mathrm{O}(\mathrm{O})}=$ Concentration of adsorbed oxygen, $\mathrm{mol} / \mathrm{kg}_{\mathrm{cat}}$

$\mathrm{C}_{\mathrm{CO}(\mathrm{O})}=$ concentration of adsorbed $\mathrm{CO}, \mathrm{mol} / \mathrm{kg}_{\mathrm{cat}}$ 
Ind. Eng. Chem. Res., Vol. 36, No. 8, 19973001

$d_{p}=$ diameter of particles, $m$

$E_{i}=$ activation energy for process $\mathrm{i}, \mathrm{kJ} / \mathrm{mol}$

$\mathrm{k}_{\mathrm{i}}=$ rate constant for reaction step $\mathrm{i}$, various units

$\mathrm{k}_{\mathrm{i} 0}=$ pre-exponential factor, various units

$\mathrm{N}_{\mathrm{s}}=$ total concentration of sites $=0.33 \mathrm{~mol} / \mathrm{kg}_{\text {cat }}$

NTP $=$ normal conditions of temperature and pressure $(0$

${ }^{\circ} \mathrm{C}, 1.013 \times 10^{5} \mathrm{~Pa}$ )

$\mathrm{p}=$ pressure in the reactor, $\mathrm{kPa}$

$\mathrm{Q}=$ total volumetric flow rate, $\mathrm{mL}(\mathrm{NTP}) / \mathrm{min}$

$\mathrm{r}_{\mathrm{ad}}=$ rate of CO adsorption step (eq 2), $\mathrm{mol} / \mathrm{kg}_{\mathrm{cat}} \cdot \mathrm{S}$

$r_{\mathrm{er}}=$ rate of Eley-Rideal step (eq 1 ), $\mathrm{mol} / \mathrm{kg}_{\mathrm{cat}} \cdot \mathrm{s}$

$r_{d}=$ rate of $C O$ reactive desorption step (eq 3 ), $\mathrm{mol} / \mathrm{kg}_{\mathrm{cat}} \cdot \mathrm{s}$

$\mathrm{R}_{\mathrm{CO}_{2}}=\mathrm{CO}_{2}$ rate of formation, mol $/ \mathrm{kg}_{\mathrm{cat}} \cdot \mathrm{S}$

$\mathrm{R}_{\mathrm{CO}}=\mathrm{CO}$ rate of disappearance, $\mathrm{mol} / \mathrm{kg}_{\mathrm{cat}} \cdot \mathrm{s}$

$\mathrm{R}_{\mathrm{j}}=$ rate of transformation of gas phase species $\mathrm{j}$, mol/ $\mathrm{kg}_{\text {cat }} \cdot \mathrm{S}$

$\mathrm{R}=$ gas constant, $\mathrm{kJ} / \mathrm{mol} \cdot \mathrm{K}$

$\mathrm{t}=$ time, $\mathrm{s}$

$t_{d}=$ characteristic diffusion time, $s$

$t_{\mathrm{d} 0}=$ characteristic diffusion time at infinite temperature, $S$

$\mathrm{T}=$ temperature, $\mathrm{K}$

$\mathrm{x}^{\prime}=$ distance from the reactor inlet, $\mathrm{m}$

$x=$ dimensionless distance from the reactor inlet $\left(=x^{\prime} / L\right)$

$y=$ molar fraction

$\mathrm{y}_{\mathrm{CO}}=\mathrm{CO}$ molar fraction

$\mathrm{y}_{\mathrm{CO}_{2}}=\mathrm{CO}_{2}$ molar fraction

$\mathrm{y}_{\mathrm{CO}, 0}=\mathrm{CO}$ molar fraction in feed

$\mathrm{y}_{\mathrm{CO}, 0}(\mathrm{t})=\mathrm{CO}$ inlet step function

$\mathrm{y}_{\mathrm{N}_{2} \mathrm{O}, 0}=\mathrm{N}_{2} \mathrm{O}$ molar fraction in feed

$z^{\prime}=$ distance from the center of the spherical geometry iron oxide crystallite, $\mathrm{m}$

$\mathrm{z}=$ dimensionless distance from the center of the spherical

geometry iron oxide crystallite $\left(z^{\prime} / \delta\right)$

( ) = lattice oxygen vacancy

$(\mathrm{O})=$ lattice oxygen

$\mathrm{O}(\mathrm{O})=$ adsorbed oxygen species

$\mathrm{CO}(\mathrm{O})=$ adsorbed $\mathrm{CO}$ species

Greek Letters

$\epsilon_{\mathrm{b}}=$ void fraction of catalyst $=0.5$

$\phi=$ degree of reduction of the catalyst

$\theta_{\mathrm{O}}=$ lattice oxygen coverage

$\theta_{\mathrm{oo}}=$ adsorbed oxygen coverage

$\theta_{\mathrm{CO}}=\mathrm{CO}$ coverage

$\rho_{\text {cat }}=$ catalyst bulk density $=373.5 \mathrm{~kg} / \mathrm{m}^{3}$

$\tau=$ space time referred to gas volume, $\mathrm{s}$

\section{Subscripts}

$0=$ inlet

ad = subscript for CO adsorption step (eq 2)

er = subscript for Eley-Rideal step (eq 1)

$\mathrm{d}=$ subscript for CO reactive desorption step (eq 3 )

diff = subscript for subsurface oxygen diffusion process

$i=$ subscript for reaction or diffusion process $(i=a d, e r$, d, or diff)

$\mathrm{j}=$ index for gas phase species $\left(\mathrm{CO}, \mathrm{CO}_{2}, \mathrm{~N}_{2} \mathrm{O}\right)$

$\mathrm{k}=$ index for surface species $((\mathrm{O}), \mathrm{O}(\mathrm{O}),(\mathrm{CO}))$

$\mathrm{s}=$ index for the surface

\section{Literature Cited}

(1) Alkhazov, T. G.; Gasan-Zade, G. Z.; Sultanov, M. Yu. Interaction of Carbon and Nitrogen Oxides with a Chromic Oxide Surface. Kinet. Katal. 1976, 17, 699.

(2) Bennett, C. O. The Transient Method and Elementary Steps in Heterogeneous Catalysis. Catal. Rev.-Sci. Eng. 1976, 13, 121.
(3) Bieranski, A.; Najbar, M. Adsorption Species of Oxygen on the Surfaces of Transition Metal Oxides. J . Catal. 1972, 25, 398.

(4) Castle, J . E.; Surman, P. L. The Self-Diffusion of Oxygen in Magnetite. The Effect of Anion Vacancy Concentration and Cation Distribution. J . Phys. Chem. 1969, 73, 632.

(5) Crank, J. The Mathematics of Diffusion; University Press: Oxford, U.K., 1957.

(6) Dekker, F. H. M. Transient Kinetics in Heterogeneous Catalysis: $\mathrm{CO}$ Oxidation and $\mathrm{NO}$ reduction over $\mathrm{Cu}-\mathrm{Cr}$ and $\mathrm{Pt}$ Catalysts, Ph. D. Thesis, Department of Chemical Engineering, Faculty of Chemistry, University of Amsterdam, The Netherlands, 1995.

(7) Gillot, B. Chemical Diffusion Coefficient in Preoxidised Magnetites and Zinc Substituted Magnetites. Effect of Oxygen Pressure. Ann. Chim. (Paris) 1981, 6, 591.

(8) Heizmann, J . J ; Becker, P.; Baro, R. Kinetics of Reduction of $\alpha \mathrm{Fe}_{2} \mathrm{O}_{3}$ to $\mathrm{Fe}_{3} \mathrm{O}_{4}$. Mem. Sci. Rev. Metall. 1973, 70, 625.

(9) I wamoto, M.; Yukihiro, Y.; Egashira, M.; Seiyama, T. Study of Metal Oxide Catalysts by Temperature-Programmed Desorption. 1. Chemisorption of Oxygen on Nickel Oxide. J . Phys. Chem. 1976, 80, 1989.

(10) I wamoto, M.; Yukihiro, Y.; Noboru, Y.; Seiyama, T. Study of Metal Oxide Catalysts by Temperature-Programmed Desorption. 3. Formation and Reactivity of Adsorbed Oxygen over $\alpha$-Ferric Oxide. Bull. Chem. Soc. J pn. 1978a, 51, 2765.

(11) I wamoto, M.; Yukihiro, Y.; Noboru, Y.; Seiyama, T. Study of Metal Oxide Catalysts by Temperature-Programmed Desorption. 4. Oxygen Adsorption on Various Oxides. J. Phys. Chem. 1978b, 82, 2564.

(12) Kiperman, S. L. Chemical Kinetics-A Searchlight for Mechanism of Heterogeneous Catalytic Reactions. Chem. Eng. Commun. 1991, 100, 3.

(13) Kobayashi, M. Transient Response in Heterogeneous Catalysis. Catal. Rev.-Sci. Eng. 1974, 10, 139.

(14) Kobayashi, M. Characterization of Transient Response Curves in Heterogeneous Catalysis-II. Estimation of the Reaction Mechanism in the Oxidation of Ethylene over a Silver Catalyst from the Mode of the Transient Response Curves. Chem. Eng. Sci. 1982, 37, 403.

(15) Randall, H.; Doepper, R.; Renken, A. Model Discrimination by Unsteady-State Operation: Application to the Reduction of $\mathrm{NO}$ with CO on Iron Oxide. Can. J . Chem. Eng. 1996a, 74, 586.

(16) Randall, H.; Doepper, R.; Renken, A. Modeling the Dynamics of the $\mathrm{N}_{2} \mathrm{O}$ Reduction on Iron Oxide. Catal. Today 1996b, accepted.

(17) Randall, H. Ph. D. Thesis, Federal Institute of Technology, Lausanne, Switzerland, 1996c.

(18) Renken, A. Transient Operation for the Purpose of Modeling Heterogeneous Catalytic Reactions. Int. Chem. Eng. 1993, 33, 71.

(19) Robert, T.; Bartel, M.; Offergeld, G. Characterization of Oxygen Species Adsorbed on Copper and Nickel Oxides by X-Ray Photoelectron Spectroscopy. Surf. Sci. 1972, 33, 123.

(20) Sazonova, I. S.; Alikina, G. M.; Glazneva, G. V.; Keier, N. P.; Bobdanchikova, N. E.; Devyatov, V. G. Charged Forms in the Chemisorption of $\mathrm{NO}$ and $\mathrm{N}_{2} \mathrm{O}$, and their Role in the Reaction of NO with Carbon Monoxide on Oxide Catalysts. Kinet. Katal. 1977, $18,441$.

(21) Simusolv, Modeling and Simulation Software, Reference Guide, Dow Chemical Company, Midland, MI, 1990.

(22) Sokolovskii, V. D. Principles of Oxidative Catalysis on Solid Oxides. Catal. Rev.-Sci. Eng. 1990, 32, 1.

(23) Tamaru, K. Dynamic Relaxation Methods. Catalysis: Science and Technology; Springler Verlag: Berlin, 1983; pp 87-129.

Received for review October 2, 1996 Revised manuscript received February 3, 1997 Accepted February 4, $1997^{\otimes}$

IE960613D

${ }^{\otimes}$ Abstract published in Advance ACS Abstracts, J une 15, 1997. 